\title{
IUNS - International Union of Nutritional Sciences
}

$\mathrm{T}$ he International Union of Nutritional Sciences (IUNS) is the umbrella organization for nutrition societies all over the world (1). It was founded in England in 1948 and was initially led by a small executive committee. The first chairs were from Belgium and the UK, Professor EJ Bigwood and Dr Leslie J Harris, respectively. In the beginning, the main aim of the Union was to support the development of nutritional science and human nutrition everywhere in the world. That aim has not changed much through the years.

The IUNS does not have individuals as members, instead a country may have a scientific society as a representative member called an adhering body of the IUNS. The Finnish Society for Nutrition Research represents Finland. Sweden, Norway, Denmark and Iceland are attached with corresponding scientific societies as adhering bodies. In 2006 the number of adhering bodies exceeded 80 .

The IUNS Council is responsible for the activities carried out by the IUNS. The council members are selected every fourth year, and the chairs have been selected from different parts of the world, from the USA, Australia, Belgium, Brazil, Egypt, England, India, Yugoslavia, the Netherlands and Thailand. There has been one chair from Scandinavia: Professor Paavo Roine from Finland in 1969-1972. The new council started its fourth year period in September 2006. The present chair, Professor Ricardo Uauy, is from Chile, and the other members are from the USA, Austria, Brazil, Egypt, South Korea, Spain and Finland.

The IUNS is a member of the International Council of Scientific Unions (ICSU), and in this forum the IUNS has collaborated with other member societies of the ICSU, such as the International Union of Toxicology, Pure and Applied Chemistry, Biochemistry and Molecular Biology and Food Science and Technology.

The mission of the IUNS is still the same as it was in the beginning: to support nutritional science in all its forms, with a particular emphasis on global issues of nutrition. The main scientific activity of the IUNS is to organize and take responsibility for the scientific programme of the World Congress of Nutrition, together with a local adhering body. These congresses take place every fourth year. The first congress was held in 1952 in Basle, and the next one will be in Bangkok in 2009. The other scientific activity of the IUNS is to be a voice in different organizations of the United Nations (UN). Having a non-governmental organization (NGO) status, a representative of the IUNS may take part in the meetings and activities of different UN organizations such as the United Nations Children's Fund (Unicef), the World Health Organization (WHO), the Food and Agriculture Organization (FAO), the International Atomic Energy Agency (IAEA) and the Sub-Committee on Nutrition (SCN) and in this way influence decisions made on this level. The third way to act is to support local committees, task forces and projects. The areas of these actions are versatile, from food production to technology and human nutrition.

The vision of the IUNS for the future was discussed and accepted in the IUNS council meeting in March 2006: "To live a life without malnutrition is a fundamental human right. The persistence of malnutrition, especially among children and mothers, in this world of plenty is immoral. Nutrition improvement anywhere in the world is not a charity but a societal, household and individual right. It is the world community's responsibility to find effective ways and means to invest for better livelihood and to avoid future unnecessary social and economic burdens. With collective efforts at international, national and community levels, ending malnutrition is both a credible and achievable goal." The mission of the IUNS was also stated: "Promote the advancement of the science of nutrition, research and development through international cooperation globally."

\section{Reference}

1. Underwood BA. International Union of Nutritional Sciences (IUNS): an overview. (www.iuns.org)

\footnotetext{
Professor Marja Mutanen (member of the IUNS Council)

Department of Applied Chemistry and Microbiology

Division of Nutrition

University of Helsinki

PO Box 66, Fl-000 I4, Helsinki, Finland
} 